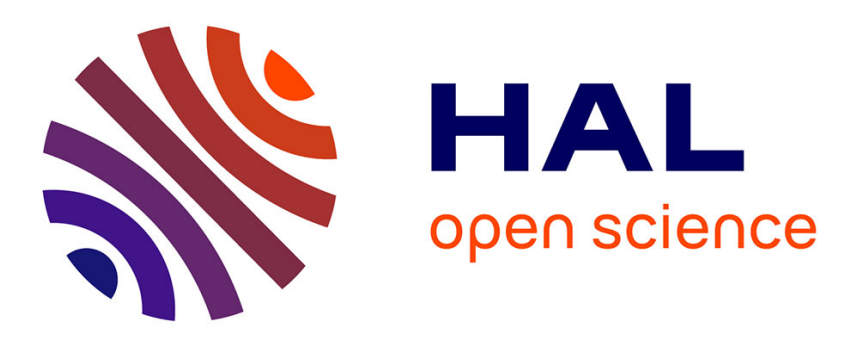

\title{
Ultra-Lean Pre-Chamber Gasoline Engine for Future Hybrid Powertrains
}

\author{
David Serrano, Jean-Marc Zaccardi, Christoph Müller, Cedric Libert, Knut
} Habermann

\section{> To cite this version:}

David Serrano, Jean-Marc Zaccardi, Christoph Müller, Cedric Libert, Knut Habermann. Ultra-Lean Pre-Chamber Gasoline Engine for Future Hybrid Powertrains. 14th International Conference on Engines \& Vehicles, Sep 2019, Capri, Italy. 10.4271/2019-24-0104 . hal-02294318

\section{HAL Id: hal-02294318 \\ https: / hal-ifp.archives-ouvertes.fr/hal-02294318}

Submitted on 23 Sep 2019

HAL is a multi-disciplinary open access archive for the deposit and dissemination of scientific research documents, whether they are published or not. The documents may come from teaching and research institutions in France or abroad, or from public or private research centers.
L'archive ouverte pluridisciplinaire HAL, est destinée au dépôt et à la diffusion de documents scientifiques de niveau recherche, publiés ou non, émanant des établissements d'enseignement et de recherche français ou étrangers, des laboratoires publics ou privés. 


\title{
Ultra-Lean Pre-Chamber Gasoline Engine for Future Hybrid Powertrains
}

\author{
Author, co-author (Do NOT enter this information. It will be pulled from participant tab in \\ MyTechZone) \\ Affiliation (Do NOT enter this information. It will be pulled from participant tab in MyTechZone)
}

\begin{abstract}
Lean burn gasoline spark-ignition engines can support the reduction of $\mathrm{CO}_{2}$ emissions for future hybrid passenger cars. Very high efficiencies and very low NOx raw emissions can be achieved, if relative air/fuel ratios $\lambda$ of 2 and above can be reached. The biggest challenge here is to assure a reliable ignition process and to enhance the fuel oxidation in order to achieve a short burn duration and a good combustion stability.
\end{abstract}

This article aims at introducing an innovative combustion system fully optimized for ultra-lean operation and very high efficiency. Thereto, a new cylinder head concept has been realized with high peak firing pressure capability and with a low surface-to-volume ratio at high compression ratios. 1D and 3D simulations have been performed to optimize the compression ratio, charge motion and intake valve lift. Numerical calculations also supported the development of the ignition system. Stable ignition and fast flame propagation were achieved thanks to a centrally located active prechamber which allows to control the air/fuel ratio independently of the air/fuel ratio in the main combustion chamber.

Experimental investigations have then been performed with a single cylinder engine to demonstrate the capabilities of this new combustion system in a sweet spot operating point. A maximal indicated thermal efficiency of $47 \%$ was achieved at $\lambda=2$ with optimized injection settings in the pre and main combustion chambers. The fuel efficiency could be maximized thanks to a fast and knock-free combustion process. Compared to the reference operation with stoichiometric air/fuel ratio, only a seventieth of the NOx raw emissions were measured (i. e. $50 \mathrm{ppm}$ ), and the particulate mass emissions were halved. The energy balance analysis points out that these promising results could be further improved by working on the reduction of the unburnt hydrocarbon emissions and by jointly optimizing the scavenging process.

\section{Introduction}

Most of the engine developments in last decades mainly aimed at lowering pollutant emissions. However, more recently, the needs to encounter global warming put a particular emphasis on greenhouse gas emissions associated with the transport sector. Consequently, ambitious vehicle fleet $\mathrm{CO}_{2}$ reduction targets have been set for lightduty vehicles all around the world and especially in Europe where a reduction of at least $37.5 \%$ must be achieved in 2030 in comparison to 2021 based upon the Worldwide harmonized Light vehicle Test Procedure (WLTP) [1].

Page 1 of 15
These targets will of course profoundly change the structure of the global automotive market with a definite evolution from pure thermal towards more and more highly electrified powertrains. It is difficult to reliably and precisely forecast what the market will look like in 2030 in this moving context. However, according to various market studies the cumulative share of gasoline hybrid vehicles (from mild to plug-in) will exceed $30 \%$ of the total worldwide sales in 2030 [2-4] with a strong variability depending on the considered markets (US, Asia, Europe, India) and on the considered scenarios for future regulations and incentives. Given the current context worldwide, these sales scenarios naturally show a strong preference for gasoline engines to the detriment of Diesel powertrains.

Although the majority of future powertrain architectures will be electrified, it will be essential to also develop highly efficient internal combustion engines to limit the constraints and requirements for the electrical components, such as the battery size. These highly efficient internal combustion engines will also maximize the overall vehicle efficiency in highway driving conditions where hybridization does not bring any major benefit. Several approaches are possible to increase the thermal efficiency. One of them is to increase the dilution level of the air-fuel mixture by means of extra air or EGR The impact on mixture heat capacity and isentropic coefficient leads to higher thermal efficiency. It is also possible to increase the compression ratio in conjunction with new technologies which reduce the knock tendency of gasoline SI engines (e.g. water injection).

Several publicly and privately funded research projects are currently on-going to develop new highly efficient internal combustion SI engines. This is the case for example in Japan with the crossministerial Strategic Innovation Promotion Program (SIP) dealing with innovative combustion technology. The works performed by the gasoline combustion team aim at developing new technologies to further improve the super-lean burn approach and to reach $50 \%$ thermal efficiency by the end of 2018 [5]. In summer 2017, single cylinder engine tests had already demonstrated a maximal indicated efficiency of $46 \%$ [5]. The interactions between the ignition system and the tumble motion were particularly analyzed in order to optimize the ignition and flame propagation processes. Jung et al. [6] have recently reported that high discharge energy combined with high tumble motion can further extend the lean limit and thus increase the maximal efficiency. In parallel, Moriyoshi et al. [7] have shown that a slight vertical fuel stratification could limit the bulk flame quenching and support the combustion process to achieve a higher indicated work. It is thus possible to reduce the cycle-to-cycle fluctuations and to slightly extend the lean limit. However, the requirements for ignition systems and charge motion might be completely different for other lean burn concepts. This is the case for 
example for the Mazda Spark Controlled Compression Ignition (SPCCI), [8] concept for which the ignition and the main combustion phases are strongly supported by auto-ignition.

Many other studies have been performed on lean burn combustion. Recently, a multi spark high energy ignition system (up to $500 \mathrm{~mJ}$ ) was combined with a variable charge motion system by Luszcz et al. [9]. They achieved a remarkable maximal net indicated efficiency of $46 \%$ with stable combustion at $\lambda=1.9$. Ratnak et al. [10] have also reported very high indicated efficiencies up to $48.2 \%$ obtained by combining a swirl motion with a dual charge dilution by air and EGR.

The European H2020 EAGLE project aims at developing a new highly efficient ultra-lean burn gasoline engine for future hybrid vehicles. The main objectives of this project are to achieve air dilution rates of $\lambda=2$ and a peak brake thermal efficiency of $50 \%$ in order to support a long term fleet target of $50 \mathrm{gCO}_{2} / \mathrm{km}$. The first section of this article is dedicated to the engine definition in terms of in-cylinder charge motion, compression ratio, valve lift, fuel injection systems and pre-chamber ignition. Then, the second part describes experimental results including the optimization procedure for the most relevant engine parameters, the comparison of various engine configurations and the demonstration of the best efficiency achieved. The last section focuses on the perspectives to further improve this new combustion system.

\section{Engine Development}

The engine concept has been optimized to achieve very high efficiencies with ultra-lean mixtures. From the bore and stroke definition, to the valve actuation, and through the in-cylinder charge motion or the fuel injection systems, all the choices made for engine architecture are oriented towards maximizing engine efficiency. The main feature of this engine concept is an active pre-chamber including a spark-plug and a fuel injector to enable an efficient ultralean combustion.

\section{Engine Architecture}

An engine bore of $76 \mathrm{~mm}$ and a stroke of $90 \mathrm{~mm}$ have been selected. Very long stroke configurations are often highlighted as being favorable to achieve high efficiencies [11], but the stroke-to-bore ratio has been deliberately limited here to comply with reasonable packaging requirements for automotive applications and because the main constraint was to reutilize an existing base engine that could be operated with peak firing pressure of up to 180 bar. However, at this time, no serial production SI engine can be operated with such high peak firing pressures and with stroke-to-bore ratios greater than 1.2 in automotive applications. Besides, it can be noted as well that the reduction of cooling losses is often emphasized for long stroke configurations because of their favorable surface-to-volume $(\mathrm{S} / \mathrm{V})$ ratio at top dead center [11]. However, in the case of the works reported here, these cooling losses are already considerably decreased thanks to the use of ultra-lean mixtures in comparison with the usual stoichiometric operation. The influence of the $\mathrm{S} / \mathrm{V}$ ratio on the indicated specific fuel consumption (ISFC) can be estimated using 1D simulations. The $\mathrm{S} / \mathrm{V}$ ratio sweep depicted in Figure 1 has been performed keeping all the other geometric parameters (such as valve diameters and cylinder displacement) constant. This approach is purely numerical as the valve diameters should be reduced when the bore is reduced but it is assumed to be the best way to compare the cooling losses. The combustion process is not modeled in these

Page 2 of 15 simulations and the heat released by combustion is considered as a boundary condition and kept constant for all the considered stroke-tobore (or $\mathrm{S} / \mathrm{V}$ ) ratios. The heat transfer model used in the 1D simulation tool is based on the Woschni correlation. Keeping in mind the assumptions and limitations related to such a model, it can be seen that for an injected fuel mass of $17 \mathrm{mg} /$ stroke corresponding to a part load operating point (around 7 bar IMEP), the ISFC benefit when increasing the $\mathrm{S} / \mathrm{V}$ ratio at $\lambda=2$ is reduced compared to the gain at $\lambda=1$.

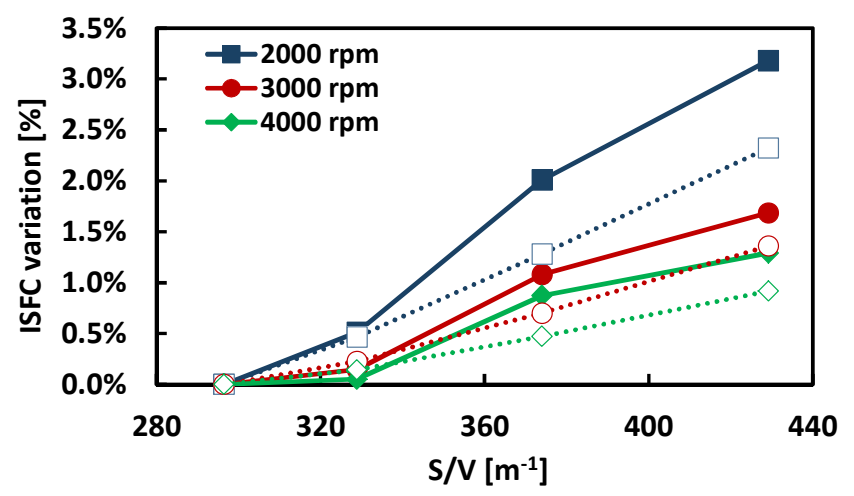

Figure 1. ISFC dependency on $\mathrm{S} / \mathrm{V}$ ratio at top dead center at $\lambda=1$ (solid lines) and $\lambda=2$ (dashed lines).

It can thus be reasonably assumed that long stroke configurations with stroke-to-bore ratios higher than 1.2 would not offer the same advantage in lean conditions as in stoichiometric conditions.

\section{In-cylinder Charge Motion}

The intake ports have then been designed taking into account three main indicators.

1. Turbulence generation: it is generally accepted that strong tumble motions and high turbulent kinetic energy (TKE) in spark-ignited engines can support a faster flame propagation process and enhance the efficiency. However, in the case of a pre-chamber engine, the requirements in terms of charge motion were not yet clearly established at the beginning of the study. Therefore, some preliminary numerical investigations have been performed to quantify the impacts of charge motion inside the main and pre-chambers on the combustion process. Results of these investigations [12] have shown that the turbulence level in the vicinity of the flame front and the overall combustion performance are mainly related to the jets coming out of the prechamber holes and to a much lesser extent to the charge motion in the main chamber generated by the intake ports. From this point of view, only low tumble motion is required.

2. Mixture preparation: the tumble motion does not only aim at producing turbulence, but also at supporting the mixture preparation process whether ignition is directly performed with a usual spark-plug or with an intermediate pre-chamber. In the case of stoichiometric mixtures, spatial variations of $\lambda$ can be accepted because the flame can still propagate except if the mixture is dramatically heterogeneous. However, when average $\lambda$ values of 2 are targeted, then the spatial $\lambda$ distribution must be as narrow as possible because the flame might not propagate in extremely lean mixtures. Therefore, from this point of view, a strong tumble motion is required to enhance the mixture 
homogenization, especially in the case of gasoline direct injection (GDI).

3. Flow capacity: high intake air flow rates are required in ultralean conditions and any decrease in the port's flow capacity could result in efficiency losses during the scavenging phase. In order to achieve $50 \%$ thermal efficiency, not only the combustion process should be optimized but also the pumping losses reduced as much as possible.

The overall trade-off between flow capacity, turbulence generation and mixture preparation has been evaluated with $3 \mathrm{D}$ steady-state calculations performed with Ansys-Fluent for different intake ports variants and considering a computational domain representative of IFPEN steady-state flow bench including the ports, the valves, and a tumble "T-tube" [13]. Figure 2 shows the tumble level and flow coefficient achieved for the new ports optimized for $\lambda=2$ operation in comparison with some state-of-the-art ports designed to generate a strong tumble motion at $\lambda=1$. In the end, the selected variant displays a moderate tumble motion, but a higher flow capacity than the reference ports.

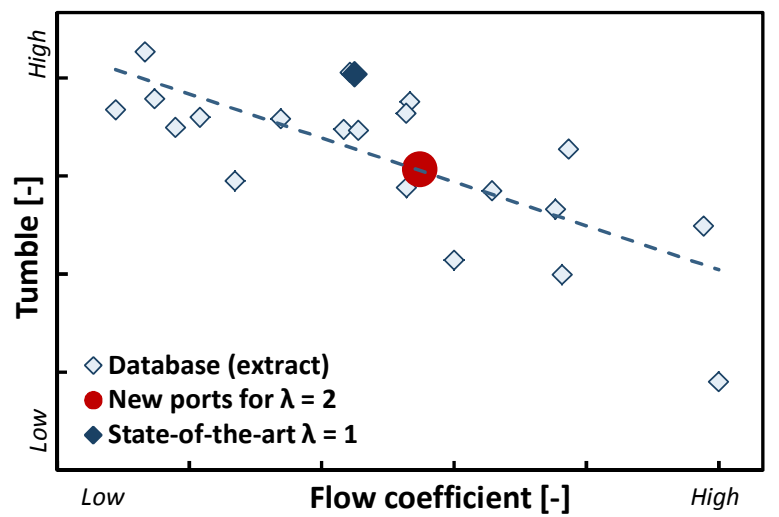

Figure 2. Flow capacity and tumble motion trade-off (3D steady-state results).

\section{Compression Ratio and Intake Valve Lift}

The compression ratio has been optimized together with the intake valve lift. In order to achieve high efficiencies, compression ratios above 14:1 have been considered along with various intake valve lifts in order to reduce the effective compression ratio. Only the results obtained with a valve lift opening duration of $123 \mathrm{CAD}$ and thus with an early intake valve closing (EIVC) timing strategy are shown here. Preliminary 3D transient CFD aeroacoustics simulations have been performed with the Converge software to predict the transient tumble motion and Turbulent Kinetic Energy (TKE) obtained in the main chamber by using similar methodology and computational domain as those shown in [12]. As it could be expected from the selected intake ports (see Figure 2), both tumble and TKE generated in the main combustion chamber are relatively low as shown in Figure 3. It can especially be observed that the reduced valve lift opening duration cannot support the generation of a high TKE level close to top dead center (TDC).

Page 3 of 15

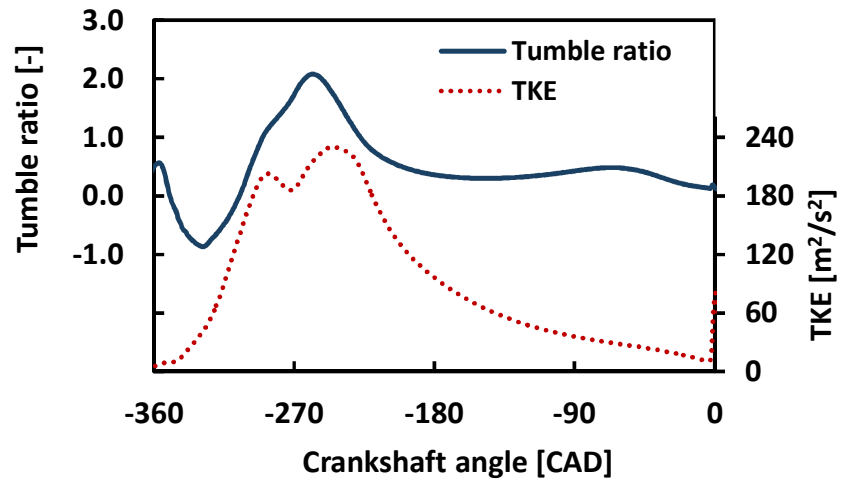

Figure 3. Tumble ratio and turbulent kinetic energy for the EIVC strategy.

Before the engine tests were started, further 3D CFD combustion simulations were performed to identify which engine configuration could achieve optimal combustion timings at $\lambda=2$ with the highest possible compression ratio. Figure 4 shows some results of these investigations performed with two spark timings, a compression ratio of 15:1 and the intake valve lift described above. A sudden increment corresponding to knock can be observed with a spark timing of 15 CAD bTDC and a MFB50 angle at around 2 CAD aTDC (i.e. too early compared to the optimal one usually expected around 7 CAD aTDC), but absolutely no knock is observed with a spark timing of 10 CAD bTDC and a MFB50 angle of around 8.4 CAD aTDC. A sufficient margin was thus identified with respect to knock showing that optimal combustion timings could be possible even with a compression ratio of $15: 1$ and the considered intake valve lift. Standard intake valve lift durations (usually around 190 CAD) have not been considered since they would obviously downgrade the knocking resistance at such high compression ratios.

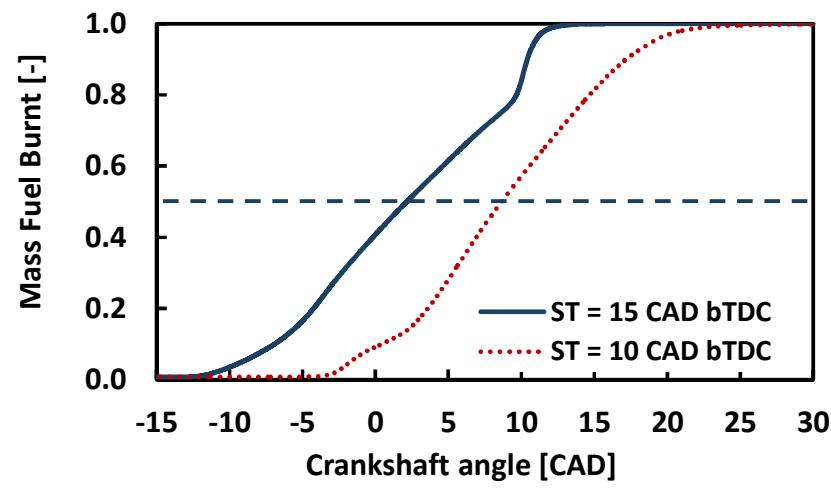

Figure 4. Mass Fuel Burnt vs crank angle (3D CFD calculations performed at $3000 \mathrm{rpm}, 13$ bar IMEP, $\lambda=2$ ).

\section{Fuel Injection Systems}

Both gasoline direct injection (GDI) and gasoline port fuel injection (PFI) have been considered for injecting gasoline into the main combustion chamber. Because of packaging constraints related to the central pre-chamber, the direct injection was implemented laterally. A specific 4-hole injector has been designed for this engine. Its spray targeting has been optimized to avoid interactions with the valves and the pre-chamber and to optimize as much as possible the mixture homogeneity at TDC. Maximal injection pressure for direct injection is 350 bar. In parallel, gasoline port fuel injection has also been 
implemented, but with a high injection pressure of 200 bar in order to enhance the fuel vaporization and to significantly improve the mixture homogenization. As mentioned above, the $\lambda$ distribution must be as narrow as possible, since the flame might not propagate in extremely lean mixtures at $\lambda>2$. A 6-hole injector usually used for direct injection has then been selected, and the $\lambda$-distributions obtained close to TDC have been checked with 3D CFD simulations (see Figure 5).

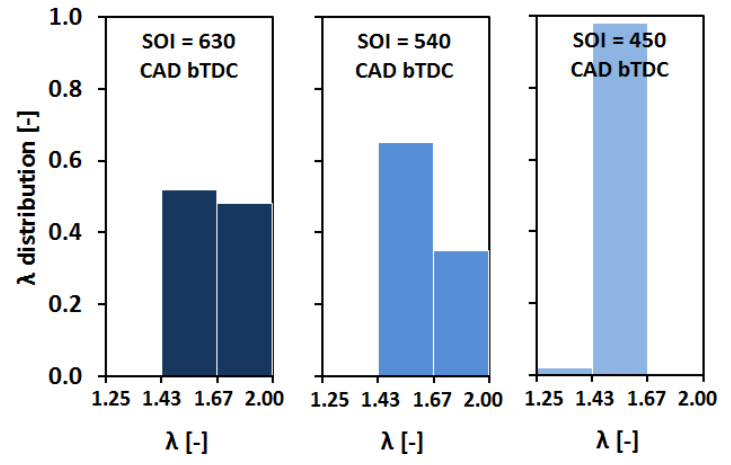

Figure 5. $\lambda$-distributions at $15 \mathrm{CAD}$ bTDC for three SOI timings.

Because of the low tumble motion, the GDI injection system leads to a poor $\lambda$ distribution in the main chamber compared to the PFI injection system. Figure 6 shows the spatial standard deviation of the $1 / \lambda$ field in the main chamber for both GDI and PFI at $20 \mathrm{CAD}$ bTDC spark timing for various start of injection (SOI) timings. The SOI timing window leading to an acceptable standard deviation is very narrow for the GDI whereas the standard deviation is almost flat for the PFI independent of the SOI

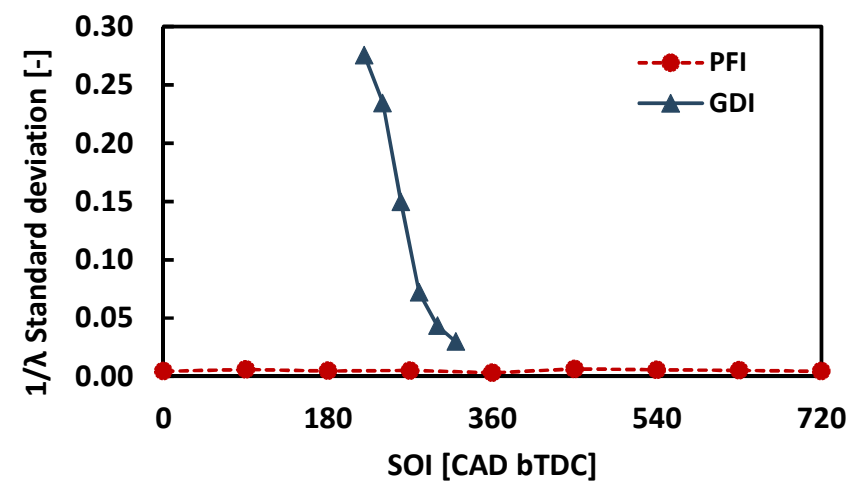

Figure 6. $1 / \lambda$ standard deviation at $20 \mathrm{CAD}$ bTDC in the main chamber as a function of SOI for both GDI and PFI.

On the one hand, it could be argued that better combustion timings are usually achieved with GDI thanks to the cooling effect of gasoline evaporation. However, this new combustion system has been developed to be operated at $\lambda=2$, and in these conditions, the knocking resistance is basically stongly improved thanks to dilution. Thus, the impact of the fuel cooling effect should be less important than at $\lambda=1$. On the other hand, it is accepted that PFI is less flexible to control any mixture stratification during the catalyst light-off phase. But here again the objective is to run the engine as much as possible at $\lambda=2$ over the whole engine map, and in any case the prechamber ignition system limits the use of this type of strategy. Specific new strategies will have to be developed for light-off phases Page 4 of 15 with a pre-chamber ignition system, as well as for the control of particle emissions with port fuel injection during cold start (both potential issues have been identified, but are not addressed in this article).

\section{Pre-Chamber Ignition}

An active pre-chamber ignition system was chosen to achieve an enhanced combustion process in ultra-lean conditions. Pre-chamber ignition systems have been developed for decades and have gained a surge of interest in recent years especially for homogeneous lean burn gasoline engines [14-15]. The development of the pre-chamber used in the works reported here is detailed in [16-17]. Two pre-chamber variants were initially designed taking into account the requirements for the integration of a spark plug with M10x1 thread as well as the use of an injector with a tip diameter of about $7.8 \mathrm{~mm}$. Weighing these requirements, a pre-chamber design with a larger volume of $1611 \mathrm{~mm}^{3}$ was compared with a pre-chamber design with a smaller $1080 \mathrm{~mm}^{3}$ version (both thus corresponding to a few percent of the total combustion chamber volume at TDC, and both with 4 holes). Transient 3D CFD simulations have been performed to optimize the overall pre-chamber design (investigations performed with Star CD for mixture formation evaluation and Star $\mathrm{CCM}+$ for outflow calculation). Figure 7 shows the flow generation as well as the TKE for the two variants at $20 \mathrm{CAD}$ bTDC. At this point in time, the airfuel mixture flows from the main combustion chamber into the prechamber (inflow phase). For both pre-chambers, a high flow velocity is apparent in the jet holes during this phase. Therefore, high turbulent kinetic energy is generated in the upper segment of the prechambers during the inflow phase. While in the large pre-chamber a tumble motion is developed, which also leads to a high TKE-level in the upper part of the pre-chamber, the reduction of the pre-chamber volume and the associated design changes simultaneously lead to a reduction in the TKE-level at the spark plug. The counter-tumble motion in the pre-chamber, initiated by the main combustion chamber tumble flow, is on a lower level due to the changed pre-chamber interior geometry. Another influencing factor refers to the spark plug positioning, which is moved slightly further outwards.

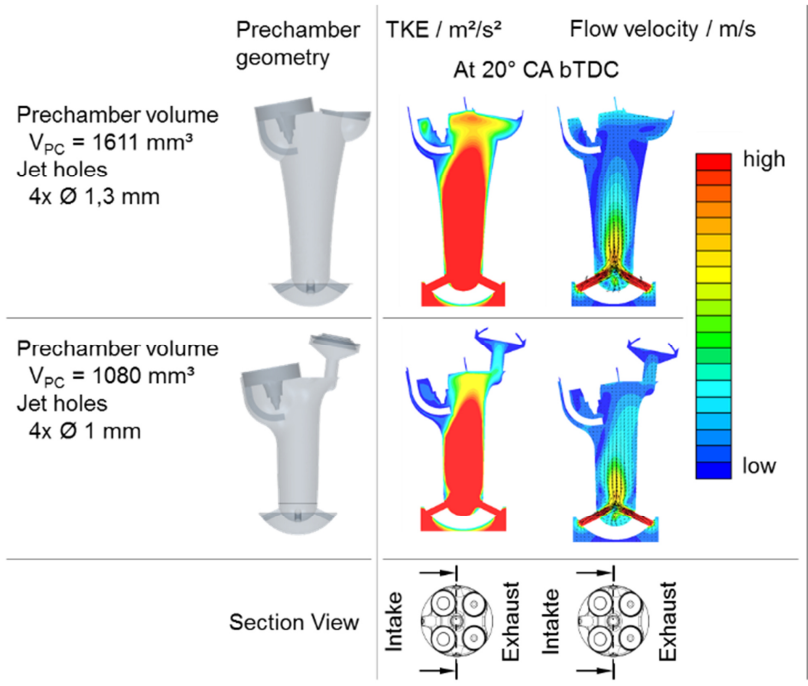

Figure 7. Flow pattern development of different pre-chamber geometries.

Taking into account the counter-tumble mechanism, the desired turbulence level target at the spark plug cannot be met. Hence, the 
transport mechanism needs to be changed. While in the two previous versions in Figure 7, the jet hole axes meet almost in one point on the central axis of the pre-chamber, the layout as in Figure 8 has an offset between the middle axis of the pre-chamber and the axis of the jets holes. Through this wind-skewed arrangement, a swirl is initiated in two or three levels each by one pair of jet holes. This swirl flow is then directed along the pre-chamber chamber wall. The mass electrode of the spark plug, turned by $180^{\circ}$ also unblocks the crosssection for the swirl flow, allowing the turbulence to penetrate closer to the spark plug.

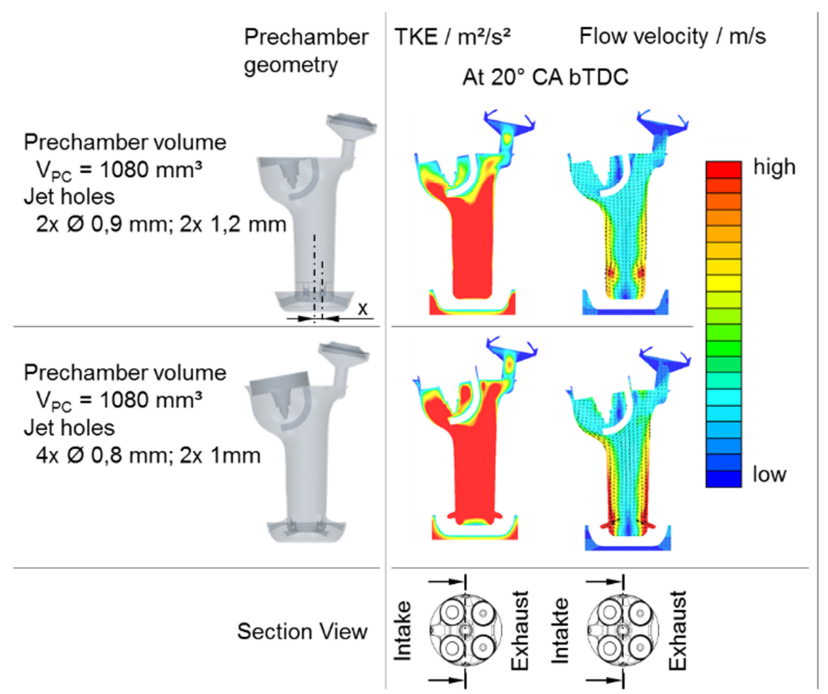

Figure 8. Flow pattern in the pre-chamber with optimized arrangement of the jet holes.

Thanks to this pre-chamber architecture, a high turbulent kinetic energy is transported to the spark plug during inflow into the prechamber, which ensures a reliable and fast combustion of the fuel air mixture. During the outflow phase, the flow through the pre-chamber jet holes reverses. The combustion starts at the spark plug in the upper volume of the pre-chamber. The flame propagation first pushes out unburnt fuel and thereafter burnt gases down and through the jet holes into the main combustion chamber.

Based on the visualization of the flow velocity in Figure 9 for the initial case (a), a further optimization of the pre-chamber inner geometry was carried out. The radius of the front chamber tip directed to the combustion chamber was reduced (b). As a result, the jet hole meets the vertical of the atrial geometry at a flatter angle. The resulting flow of the outgoing mass (indicated in red) is thus reduced from a pointed to a blunt angle. A reduction in the effective flow cross-section at the exit due to flow separation is basically avoided.

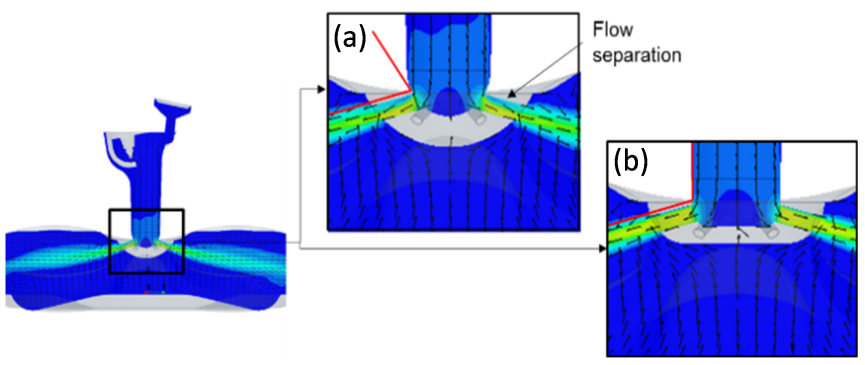

Page 5 of 15
Figure 9. Modification of the inner pre-chamber geometry from (a) to (b) to achieve optimized outflow.

In addition to the reference variant with 4 holes described above (see Figure 10 (b)), a conventional radial arrangement of the jet holes according to Figure 10 (a) was also realized as well as an alternative design with 6 holes (see Figure 10 (c)). Here, the jet hole orifices were laid out with the same diameter, but, in reference to the variant shown in lower section of Figure 8, went without the radial offset and thus, the swirl formation in the pre-chamber. This design has a significantly reduced TKE-level at the spark plug compared to the optimized variants (b) and (c). At the end, the CFD-optimized design (b) with 4-holes for the pre-chamber was selected for the single cylinder engine tests based upon the test results already reported in [16].
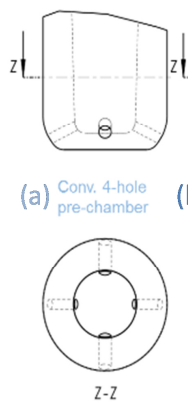

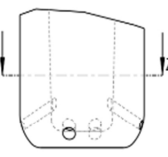

b) 4 -
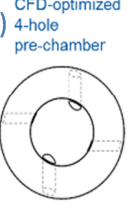

$z-z$

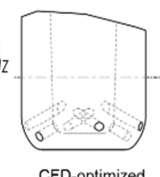

(c) 6-hole

c) 6-hole

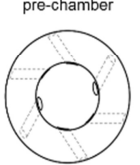

2-z

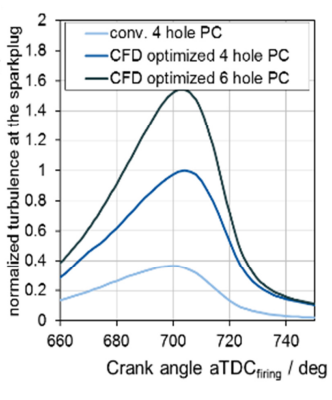

Figure 10. Different pre-chamber jet hole layouts for the testing at the SCE.

\section{Active Pre-Chamber With Gas Injection}

In the application of an active pre-chamber, gas direct injection offers various advantages. In addition to a targeted residual gas scavenging, gas injection also avoids liquid fuel impingement on the wall. Figure 11 shows the geometrical arrangement of the spark plug and the direct gas injector for the integration into the pre-chamber housing. The dosed gas flows from the injector bore into the pre-chamber via a small transfer channel. This is the only way to achieve the prechamber volume presented above. In addition, the reduced crosssection increases the flow speed and, in combination with the recess incorporated into the pre-chamber tip, is intended to realize an improved scavenging of the residual gas at the spark plug by redirection of the injected gas.
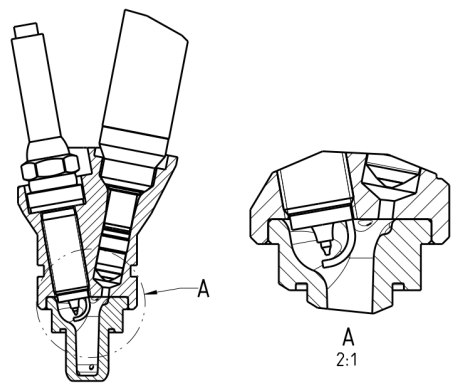

Figure 11. Cross-section of the pre-chamber with gas direct injection.

During the compression phase, in addition to the fresh air mass, also evaporated gasoline from the injection event in the main combustion chamber injection flows into the pre-chamber. This process reduces the residual gas content and at the same time, the rich mixture at the 
spark plug is diluted by the lean mixture, so that near stoichiometric conditions should be reached close to the spark-timing.

Figure 12 visualizes the spatial development of the air-fuel mixture separately for the shares of gasoline from the main combustion chamber as well as the methane from the pre-chamber gas injection. During the compression phase, due to the swirl flow, the air-gasoline mixture from the main combustion chamber is transported mainly along the pre-chamber wall upwards towards the spark plug (see top of Figure 12). In doing so, it gradually dilutes the rich methane-air mixture. At 20 CAD bTDC, the gasoline has penetrated into the prechamber leading to a rather homogeneous air-fuel mixture. The methane forms a central zone at the pre-chamber roof, which dilutes further with increasing crank angle. Spark advance should be adjusted to meet a close to stoichiometric $\lambda$ at the spark plug. One should notice that the air/gas mixture remains rich in the small volume above the transfer channel between gas injector and the rest of the pre-chamber. This pre-chamber specific geometry is necessary for the gas injector implementation but it could lead to higher particle formation and residual gas increase.

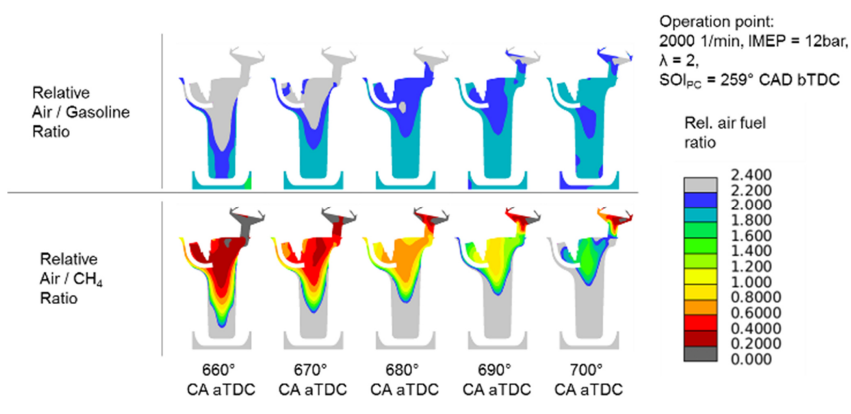

Figure 12. Relative air / gasoline vs. air / methane ratio in the pre-chamber.

\section{Active Pre-Chamber With Gasoline Injection}

The integration of the gasoline direct injection was realized via design adaptation of the pre-chamber housing. A specific injector with a diameter of $6 \mathrm{~mm}$ is used to inject the liquid fuel. Due to less space required compared to the injector for gas direct injection, there is no transfer channel between the injector tip and the pre-chamber volume. The integration into the pre-chamber housing is shown in Figure 13.

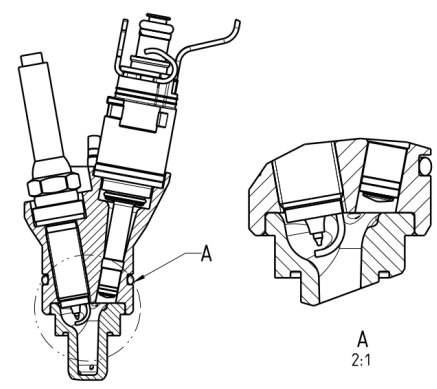

Figure 13. Cross-sectional view of the pre-chamber with gasoline direct injection.

The injection valve meets the usual series specifications of a solenoid injector, but is specifically designed for the desired spray pattern as well as the injection quantity of this application. For this purpose,

Page 6 of 15 various enrichment strategies were examined in advance by means of CFD simulations.

In a first concept (on top of Figure 14), the orientation of the injection jet was chosen such that a maximum injection path length is available. The goal was a moderate residual gas scavenging as well as a highest possible mixture homogenization in the pre-chamber with minimum wall film formation. For this purpose, a rich mixture is generated at an early stage during the intake phase and being diluted with mixture from the combustion chamber during the compression phase.

In contrast thereto, the second concept (on the bottom left-hand corner of Figure 14) aimed at directly affecting the air-fuel mixture at the spark plug. For this purpose, the injection jet in the pre-chamber was directed close to the spark plug without actually impinging it. In addition, the amount of fuel was reduced and injected far later during the compression phase.

Figure 14 shows a comparison of the two concepts. Despite the lower injection volume, the second concept achieved an almost identical air-fuel mixture at the spark plug after fuel injection into the prechamber. The smaller fuel injection quantity as well as the higher pressure in the pre-chamber at the start of injection reduces the absolute initial wall impingement. Due to the reduced time to evaporate the fuel wall film, however, a higher proportion of fuel remains attached to the wall until ignition.

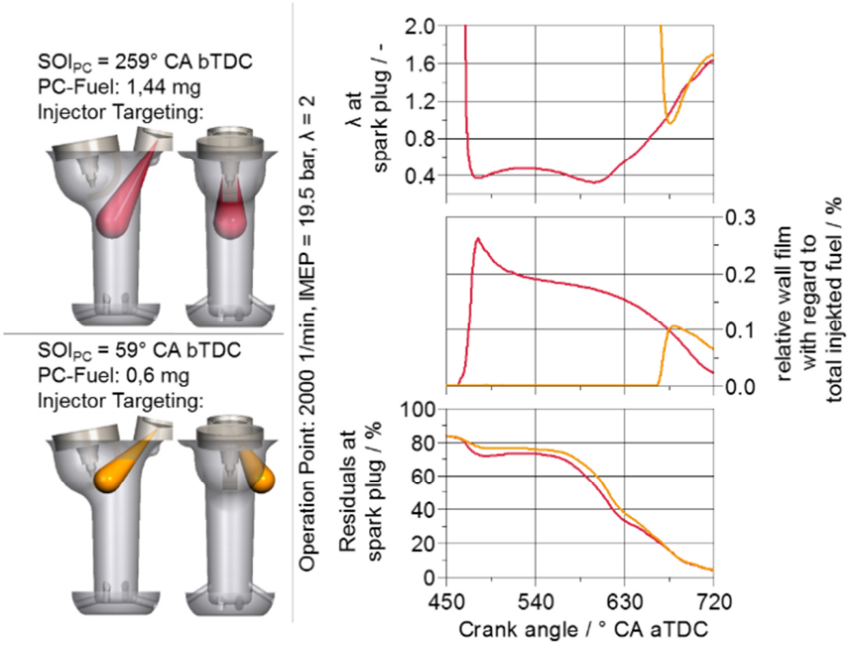

Figure 14. Progression of $\lambda$ in the pre-chamber with gasoline direct injection into the pre-chamber.

The residual gas content remaining in the pre-chamber differs for both concepts due to the different injection times. They approach each other during the compression phase (after injection has taken place also in the second concept). As a result, both concepts achieve a similar minimum residual gas content.

In order to improve the lean burn capability by means of late prechamber injection as well as a more homogeneous $\lambda$ distribution at the spark plug, the second design of the injection valve for the test bench investigations was selected despite the disadvantages listed above. 
For further results and understanding of these basic pre-chamber investigations, please refer to previous publications [16-17].

\section{Single Cylinder Engine Definition}

The newly developed combustion system has been characterized in a single cylinder engine (see Table 1). Numerous engine configurations have been tested but only a limited number of them are presented in the following section. Based on the CFD simulation results presented above, it was decided to choose a compression ratio of 15:1 for the test campaign together with an EIVC strategy (intake valve lift duration of 123 CAD). The intake and exhaust camshafts were phased in order to obtain maximum positive valve overlap. As detailed in the engine development section, two pre-chambers were manufactured for the tests: one with gas injection at 6 bar and the second one with gasoline injection at 200 or 350 bar. It can be noted that the gas injection pressure was reduced down to 6 bar in order to lower as much as possible the fuel mass flow rate in the pre-chamber. Besides, both GDI and PFI were implemented on the single cylinder engine for fuel injection into the main combustion chamber. Gasoline injection pressure was 350 bar for GDI and 200 bar for PFI. If GDI was used for main gasoline injection, injection pressure in the prechamber was set to 350 bar, whereas it was 200 bar in case of PFI for main gasoline injection.

Table 1. Single cylinder engine main characteristics.

\begin{tabular}{|l|l|l|}
\hline Cylinder displacement & {$[\mathrm{cm} 3]$} & 408 \\
\hline Valves & {$[-]$} & 4 \\
\hline Stroke & {$[\mathrm{mm}]$} & 76 \\
\hline Bore & {$[\mathrm{mm}]$} & 90 \\
\hline Compression ratio & {$[-]$} & $15: 1$ \\
\hline \multirow{2}{*}{ Pre-chamber } & $\mathrm{N}^{\circ} 1$ & Gas injection (6 bar) \\
\cline { 2 - 3 } & $\mathrm{N}^{\circ} 2$ & Gasoline injection $(200$ or 350 bar $)$ \\
\hline \multirow{2}{*}{ Main injection } & $\mathrm{N}^{\circ} 1$ & GDI $(350$ bar) \\
\cline { 2 - 3 } & $\mathrm{N}^{\circ} 2$ & PFI $(200$ bar) \\
\hline Intake valve lift duration & {$[\mathrm{CAD}]$} & $123 @ 1$ mm lift \\
\hline EVC/IVO @ 1 mm lift & {$[\mathrm{CAD}$ aTDC $]$} & $+14 /+3$ \\
\hline Max. cylinder pressure & {$[\mathrm{bar}]$} & 180 \\
\hline
\end{tabular}

\section{Experimental Results}

\section{Experimental Setup}

At the test bench, pressurized intake air was provided by an external compressor through a sonic flowmeter. For all the tests, the intake temperature was set to $40^{\circ} \mathrm{C}$. A flap was used in the exhaust line to simulate the backpressure of a real turbocharging system. Depending on the tests, the position of this exhaust flap was adjusted in order to set the exhaust pressure to the requested value. For PFI configuration, pressure differential between intake and exhaust was set to zero. For GDI and as camshafts were phased for positive valve overlap, the pressure differential was maintained at a positive value in order to take advantage of the mixture scavenging effect.

The fuels used for these tests were pure methane and standard E10 gasoline. Ignition timings, gas and gasoline injection timings were controlled with an in-house control module. A Bronkhorst flowmeter

Page 7 of 15 with a range of $[0 ; 50] \mathrm{L} / \mathrm{min}$ was used to measure the gas quantity injected in the pre-chamber. The global gasoline consumption was measured by a low pressure (LP) Coriolis Micromotion Elite CFM10 mass flowmeter located upstream the gasoline high pressure pump. A gasoline fuel rail distributes the gasoline in each of the three possible injection locations (pre-chamber, GDI or PFI). The gasoline mass flow rate (MFR) injected in the pre-chamber was measured by a high pressure (HP) Coriolis flowmeter. Thus, the gasoline mass flow rate in the main chamber can be obtained by subtracting the measure from the HP flowmeter to that of the LP flowmeter. Extremely low injection durations and fuel flow rates were used in the pre-chamber. This means that a shot-to-shot deviation can be expected for the prechamber injector. Besides, small rail pressure oscillations can alter the shot-to-shot repeatability. These observations show that existing direct injection systems are not designed to inject such small amounts of fuel and that the measure of the mass flow rate injected in the prechamber could be inaccurate. In the end, the consistency of each fuel mass flow rate was validated by the measure of LP Coriolis flowmeter.

Oil and coolant were supplied by external electrically driven pumps and temperatures were kept constant at $90^{\circ} \mathrm{C} \pm 2^{\circ} \mathrm{C}$.

The combustion was monitored by two different pressure transducers, one in the pre-chamber and another one in the main combustion chamber, the latter being used as reference for heat release rate analysis. The pressure signals were recorded with an angular resolution of $0.1 \mathrm{CAD}$ for 300 consecutive engine cycles. The mean cycle is used as a reference for performing the heat release rate analysis.

Real time engine-out emissions ( $\mathrm{HC}, \mathrm{CH}_{4}, \mathrm{CO}, \mathrm{CO}_{2}, \mathrm{O}_{2}$ and $\mathrm{NOx}$ ) were measured with Horiba MEXA-7100DEGR analyzer. Filter Smoke Number (FSN) was measured with an AVL415S Smokemeter. Particle number and mass were measured with a Pegasor Particle Sensor. The reference relative air-fuel ratio $\lambda$ was determined based upon the exhaust gas composition. $\lambda$ is therefore a global value including pre-chamber and main combustion chamber. In the same way, if gas (for pre-chamber) and gasoline (for main chamber) are simultaneously used, then the indicated thermal efficiency takes into account both fuels.

The tests were conducted in steady-state conditions and were focused at $3000 \mathrm{rpm}$ engine speed and $13 \mathrm{bar}$ IMEP. This operating point was selected based upon previous investigations as it was expected to be close to the sweet spot with maximal indicated efficiency. The maximal brake thermal efficiency is usually obtained between 2000 and $3000 \mathrm{rpm}$, and between 8 and 12 bar BMEP for highly efficient engines using compression ratios around 13:1 (as shown for example in $[5,9,11])$. However, in terms of indicated efficiency and IMEP, the maximal thermal efficiency is usually expected between 2500 and $3000 \mathrm{rpm}$ and for IMEP around $13 \mathrm{bar}$.

\section{Engine Settings Optimization For Pre-Chamber Operation}

The target was to operate at $\lambda=2$ with optimal engine settings. The combustion process of an active pre-chamber SI engine is ruled by three main engine settings that have to be tuned:

1. Start of injection timing for the main gasoline injection (SOI main).

2. Fuel mass flow rate injected into the pre-chamber (MFR PC). 
3. Start of injection timing for the pre-chamber injection (SOI PC).

For all of the tested engine configurations, these three engine settings were optimized in this order by performing three successive single parametric variations at constant $\lambda=1.67$ which approaches $\lambda=2$, but at the same time is sufficiently low to be sure that all engine configurations can be operated at this dilution level. After each single parametric variation, the optimal setting was identified and applied for the following tests. Finally, once all the engine settings were tuned, a $\lambda$ variation was performed in order to evaluate the lean-burn limit and the maximal indicated thermal efficiency (ITE).

\section{SOI Timing for the Main Gasoline Injection}

Figure 15 shows the effect of the gasoline SOI timing in PFI mode with both gas and gasoline injection into the pre-chamber. The green area on the charts represents the intake valve opening duration and the stars are highlighting the optimal settings with respect to the overall trade-off between indicated thermal efficiency and pollutant emissions. The unburnt energy is depicted and corresponds to the unburnt hydrocarbons $(\mathrm{uHC})$ and $\mathrm{CO}$ emissions in respect of the fuel total energy. It has to be noted that these tests have been performed with fixed injection settings in the pre-chambers as detailed in Table 2

Table 2. Pre-chamber injection settings for main gasoline SOI timing variation (3000 rpm, 13 bar IMEP, $\lambda=1.67$ )

\begin{tabular}{|c|c|c|}
\hline Injection settings & Gas injection & Gasoline injection \\
\hline Injection pressure in PC $[\mathrm{bar}]$ & 6 & 200 \\
\hline SOI PC [CAD bTDC] & 380 & 300 \\
\hline MFR PC $[\mathrm{kg} / \mathrm{h}]$ & 0.1 & 0.025 \\
\hline
\end{tabular}

With gasoline injection in the pre-chamber, late and early SOI timings in the main chamber maximized the indicated thermal efficiency, whereas this efficiency continuously increased when increasing the SOI timing if the pre-chamber is fed with gas. Injecting during intake valve opening was not optimal as a slight increase of unburnt energy was observed on Figure 15 (b). This could be caused by mixture scavenging as a positive valve overlap was used. Figure 15 (c) illustrates that high smoke emissions occurred with the gas pre-chamber. This was not the case for the gasoline prechamber. The SOI sweep was stopped at $540 \mathrm{CAD}$ bTDC as very high smoke emissions occurred with even earlier SOIs in the case of gas pre-chamber.

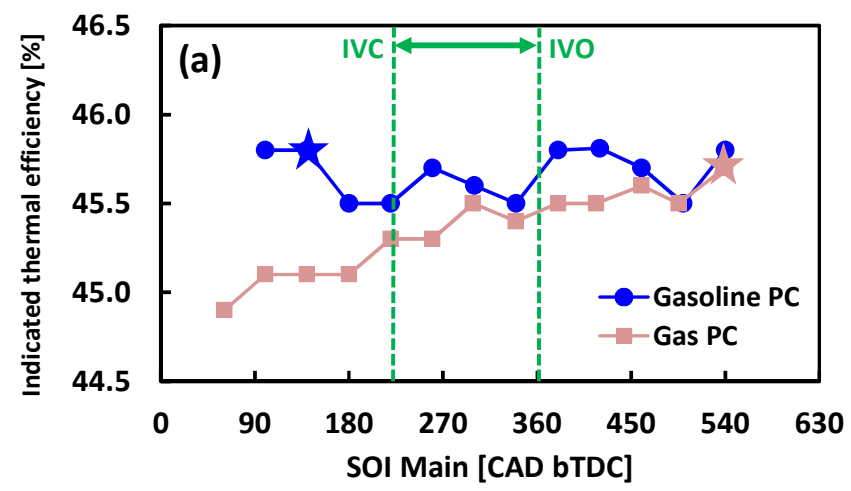

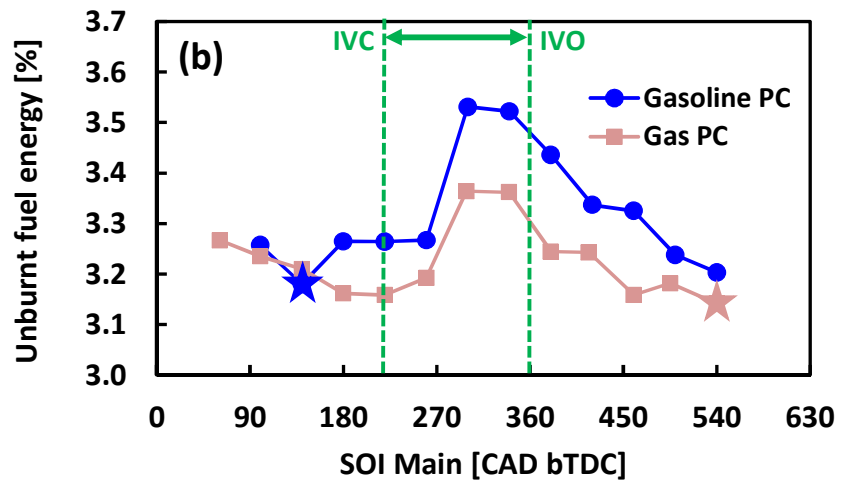

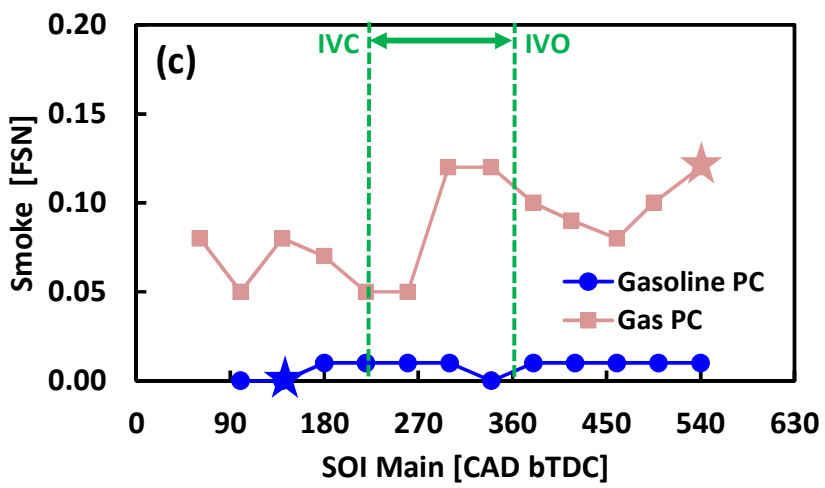

Figure 15. Impacts of SOI timing with gas and gasoline injection into the prechamber (3000 rpm, 13 bar IMEP, $\lambda=1.67$ ).

The differences in ITE evolution and emissions are not only related to the fuel type in the pre-chamber, but can also be explained by the different injection settings in the pre-chamber (see Table 2). Indeed, the fuel mass flow rate in the gas pre-chamber was four times higher than for the gasoline pre-chamber, at 0.1 and $0.025 \mathrm{~kg} / \mathrm{h}$ respectively, corresponding both to the minimal mass flow rates that could be achieved with the considered injectors. Because of these different settings, the overall fuel concentration in the pre-chamber and especially in the vicinity of the spark-plug is not the same for both pre-chambers during the intake and compression strokes. Therefore, the optimal $\lambda$ distribution in the pre-chamber could not be achieved with similar optimal injection settings in the main chamber.

When the gasoline pre-chamber is used, a late injection into the ports was selected as optimal (at 140 CAD bTDC). When the gas prechamber was used, then an early injection into the ports was selected as optimal (540 CAD bTDC).

Regarding smoke emissions shown in Figure 14 (c), some additional tests were carried out by running the engine with and without gas injection in the pre-chamber. In the latter case, the pre-chamber is called "passive" whereas in the other case, it is called "active". The gasoline mass flow rate of the main injection was increased in passive mode to maintain the same IMEP as in active mode but the other settings such as SOI timing in the main chamber and spark timing remained the same. Two engine points have been tested at $2000 \mathrm{rpm}, 10 \mathrm{bar}$ IMEP at $\lambda=1.22$ and $3000 \mathrm{rpm}, 13 \mathrm{bar}$ IMEP at $\lambda=1.43$. These $\lambda$-values have been selected as they allowed stable engine operation in passive pre-chamber mode. Figure 16 shows that no smoke emissions could be measured in passive mode during these tests. Therefore, it can be assumed that the active pre-chamber is 
certainly over-fueled (by gas but also gasoline) and that the resulting rich $\lambda$ values in the pre-chamber lead to soot formation.

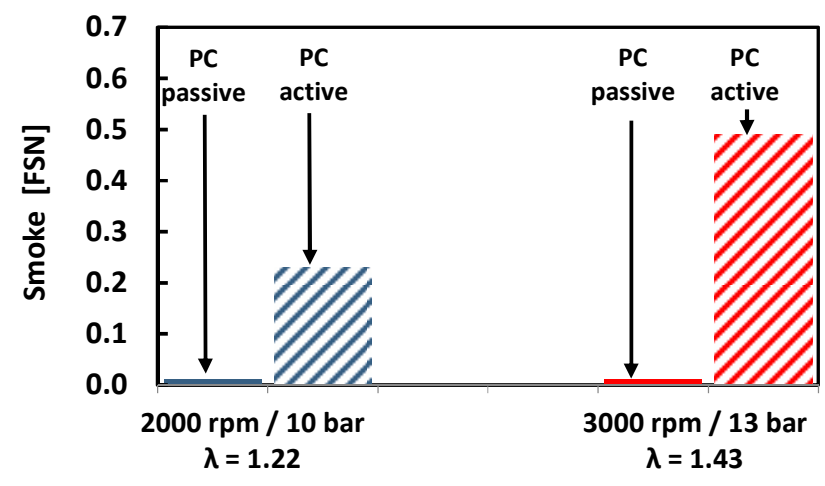

Figure 16. Comparison of activated and deactivated gas pre-chamber.

\section{Fuel Mass Flow Rate in the Pre-Chamber}

Figure 17 presents a variation of gasoline mass flow rate injected in the pre-chamber with PFI main injection. The injection settings are summarized in Table 3.

Table 3. Injection settings for pre-chamber fuel mass flow rate variation (3000 rpm, 13 bar IMEP, $\lambda=1.67$ )

\begin{tabular}{|c|c|c|}
\hline Injection settings & Main chamber & Pre-chamber \\
\hline Injection pressure in PC [bar] & 200 & 200 \\
\hline SOI [CAD bTDC] & 140 & 380 \\
\hline
\end{tabular}

Gas pre-chamber results are not presented in this article. The objective was to inject the optimal amount of fuel into the prechamber in order to get a close to stoichiometric $\lambda$ at the spark plug. It should be remembered that the $\lambda$ in the vicinity of spark plug depends on the complex combination of three effects (see Figure 12):

1. The transport mechanisms involved during the inflow phase of air-gasoline mixture coming from main chamber into the prechamber.

2. The SOI timing of the main injection that can also affect the fuel distribution around the pre-chamber holes.

3. The gasoline mass flow rate injected into the pre-chamber.

Figure 17 (a) shows that the higher indicated thermal efficiency is obtained with the smallest injected quantity in the pre-chamber $(0.022 \mathrm{~kg} / \mathrm{h})$. It can also be observed that the efficiency is reduced when this injected quantity is increased. In this case, it can be assumed that the relative air-fuel ratio close to the spark plug is getting too low because of this over-fueling. Accordingly, Figure 17 (b) and (c) show high carbon monoxide and smoke emissions for the highest fuel mass flow rate in the pre-chamber $(0.070 \mathrm{~kg} / \mathrm{h})$, confirming the over-fueling. Here again, it must be noted that these tests were performed with fixed SOI timings for the main and prechambers. It has generally been observed on various engine configurations that the highest efficiencies were obtained with the lowest fuel flow rates in the pre-chamber. It can be noted that different results might be obtained with other SOI timings, and also that the relationship between the maximal thermal efficiency and the minimal injected fuel quantities is not always so obvious. In some cases, a slight increase in injected fuel quantity could help in stabilizing the combustion process and thus in gaining in thermal efficiency.
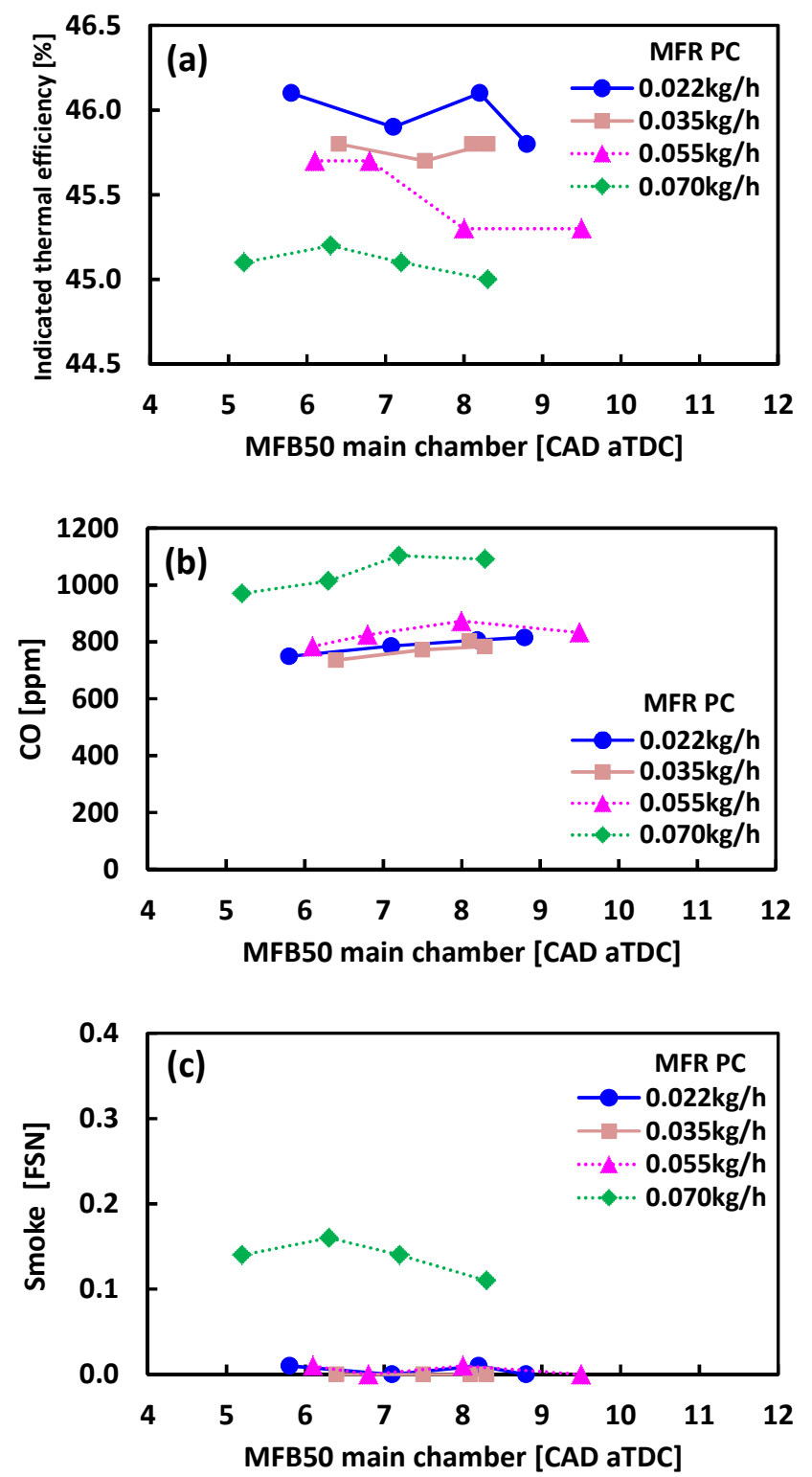

Figure 17. Impacts of gasoline mass flow rate in the pre-chamber with PFI main injection (3000 rpm, 13 bar IMEP, $\lambda=1.67$ ).

The optimal gasoline mass flow rate in the pre-chamber was then identified as $0.022 \mathrm{~kg} / \mathrm{h}$. It corresponds to the minimal injection amount that the pre-chamber injector could deliver (for this operating point, this mass flow rate corresponds to injected fuel amounts of around $0.30 \mathrm{mg}$ per cycle). This observation raised the issue of dosing of very small amounts of gasoline fuel into the pre-chamber. Existing direct injection systems are not designed for such uncommon layout targets. This issue represents a hardware limitation for this new combustion system. 


\section{Start of Injection Timing for the Pre-Chamber}

Figure 18 shows the impacts of the SOI timing in the pre-chamber when used with either gas or gasoline. These tests have been performed with port fuel injection for the main chamber and the main settings are summarized in Table 4.

Table 4. Injection settings for pre-chamber SOI variation (3000 rpm, 13 bar IMEP, $\lambda=1.67$ ).

\begin{tabular}{|c|c|c|}
\hline Injection settings & Gas injection & Gasoline injection \\
\hline Injection pressure in PC $[\mathrm{bar}]$ & 6 & 200 \\
\hline MFR PC $[\mathrm{kg} / \mathrm{h}]$ & 0.1 & 0.025 \\
\hline SOI MC $[\mathrm{CAD}$ bTDC] & 540 & 140 \\
\hline
\end{tabular}

The main observation in Figure 18 (a) is that SOI timing in the prechamber has no significant impact on indicated engine efficiency except for very early injections where unburnt fuel energy increased (see Figure 18 (b)) making the ITE to decrease drastically. Thus, the optimal SOI timing for the pre-chamber was selected for medium range at $300 \mathrm{CAD}$ bTDC for pre-chamber fed with gasoline, and 340 CAD bTDC for the pre-chamber fed with gas. The PN emissions are compared in Figure 18 (c) to highlight once again the overall bad performance observed when gas is injected in the pre-chamber. Here again, the fuel type is not the main reason explaining this high emissions but the fuel amount.
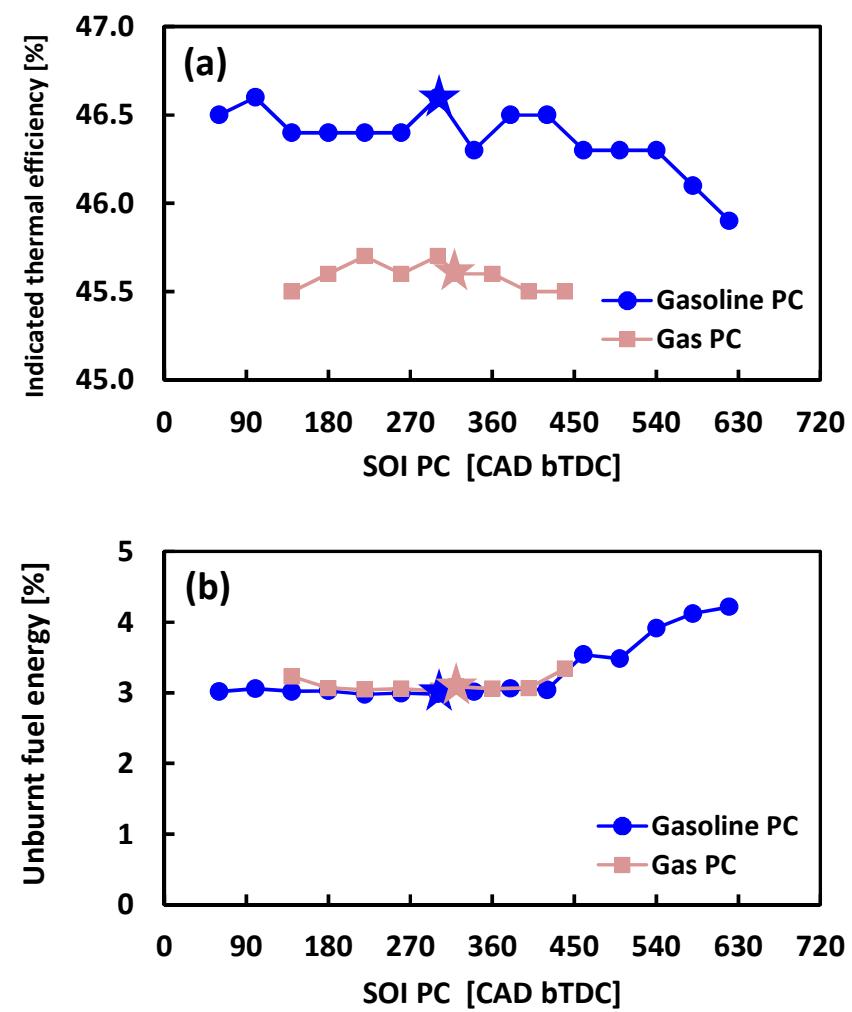

Page 10 of 15

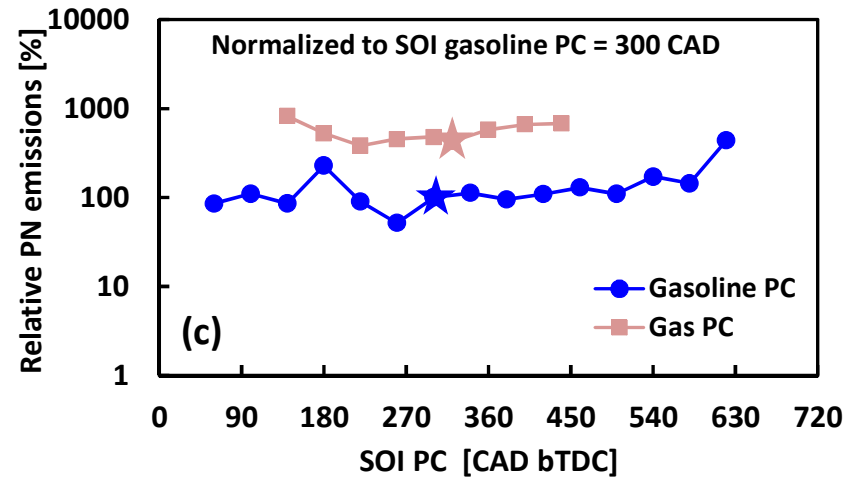

Figure 18. Impacts of the SOI timing in the pre-chamber with gas and gasoline injection into the pre-chamber and port injection for the main chamber (3000 rpm, 13 bar IMEP, $\lambda=1.67$ ).

\section{Comparison of Main Chamber Gasoline Port Fuel and Direct Injection}

The objective of these tests was to identify whether GDI or PFI is the most efficient injection mode for the main chamber. The main injection mode combined with in-cylinder charge motion has a great impact on mixture homogenization. Moreover, as shown above in the CFD calculations, the major part of fuel available in the pre-chamber comes from the gasoline main injection, meaning that optimizing the main injection location is also necessary for an efficient combustion initiation. Otherwise, the $\lambda$ conditions at the spark plug may not be optimal leading to poor combustion initiation.

For comparison, the tests were operated with the gas pre-chamber. The differential pressure between intake and exhaust was set at the optimal value for each main injection configuration as mentioned in the experimental setup section. The previously optimized engine settings optimization were applied for both GDI and PFI and led to different optimal settings (see Table 5). The fuel mass flow rate in the pre-chamber was optimized at $\lambda=1.67$ but it was kept constant at this optimal value for the whole $\lambda$ variation. Therefore, depending on the global relative fuel-air ratio, the pre-chamber could be in overfueling or under-fueling conditions. This methodology will be improved in the future to avoid test result dependency on the fuel mass flow rate injected in the pre-chamber.

Table 5. Injection settings for GDI and PFI $\lambda$ variation $(3000 \mathrm{rpm}$, 13 bar IMEP).

\begin{tabular}{|c|c|c|}
\hline Injection settings & GDI & PFI \\
\hline Injection pressure in PC [bar] & 350 & 200 \\
\hline MFR PC $[\mathrm{kg} / \mathrm{h}]$ & 0.10 & 0.10 \\
\hline SOI PC [CAD bTDC] & 300 & 360 \\
\hline SOI MC [CAD bTDC] & 300 & 540 \\
\hline
\end{tabular}

The $\lambda$ variation was stopped when the IMEP coefficient of variation (CoV IMEP) was higher than 3\% threshold (see Figure 19). Therefore, for each configuration, the highest $\lambda$ value shown in the following figure is the only operating point for which the CoV IMEP was greater than $3 \%$. The first observation was that the $\lambda=2$ target was not achieved with gas pre-chamber whatever the main injection configuration was. 

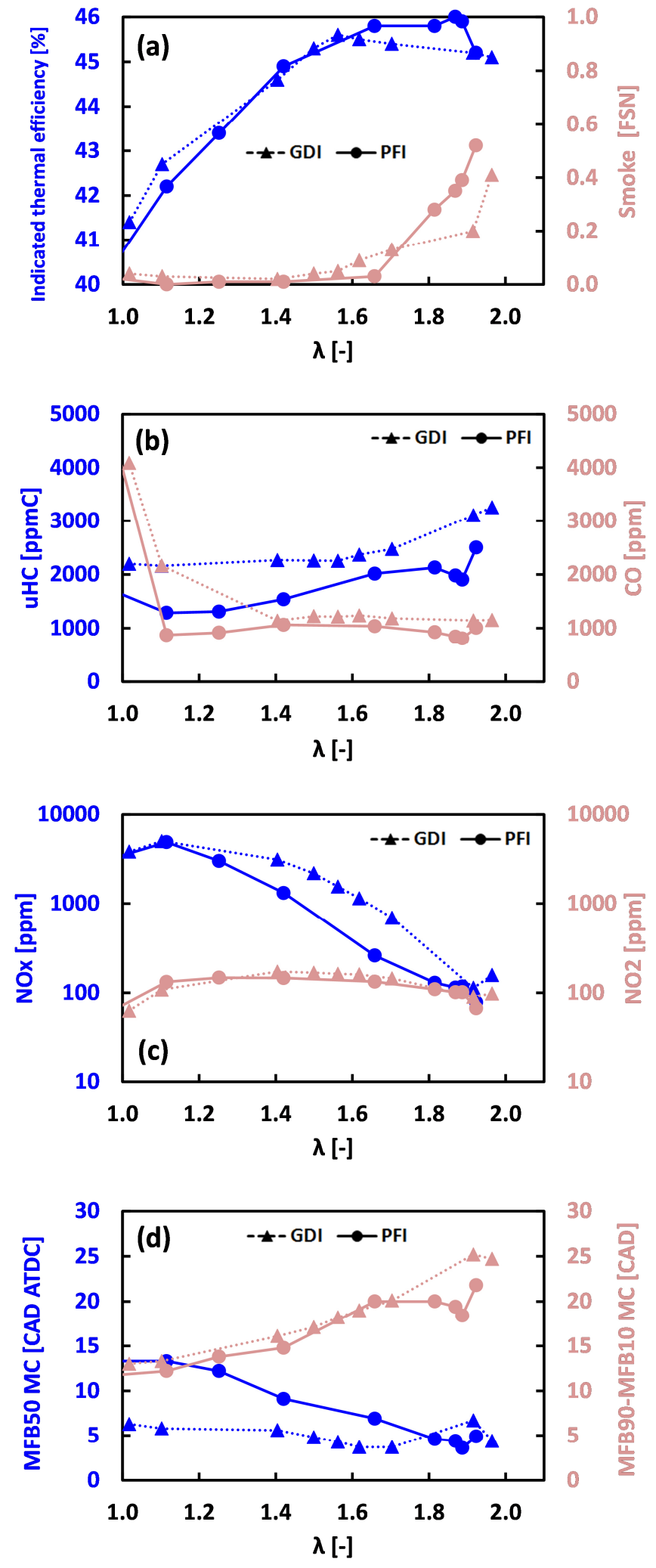

Figure 19. $\lambda$-variation for PFI and GDI in the main chamber using the gas prechamber (3000 rpm, 13 bar IMEP).

Basically, PFI was found to be the optimal configuration for main gasoline injection when the efficiency/pollutants trade-off is Page 11 of 15 considered. PFI allowed to reach $46 \%$ ITE at $\lambda=1.9$, whereas it was limited to $45.2 \%$ for GDI as depicted in curve (a). The loss in ITE observed with GDI was mainly due to increases in uHC and CO compared to PFI ( +1000 ppmC and $+400 \mathrm{ppm}$ respectively). It is also interesting to note that lower efficiencies are achieved with GDI, even if a positive pressure differential between intake and exhaust was used. Pumping mean effective pressure (PMEP) was -0.48 bar for PFI and -0.17 bar for GDI. In other words, with the same positive pressure differential, the PFI configuration might have led to even higher efficiencies despite a potential fuel scavenging

In Figure 19 (c), the NOx emissions at the lean burn limit were decreased down to around $100 \mathrm{ppm}$ at $\lambda=1.9$. It can also be observed that the $\mathrm{NO}_{2}$ to NOx ratio increased exponentially with air dilution until reaching $98 \%$ at $\lambda=1.9$. Similar trends have been reported by Luszcz et al. [9] for an ultra-lean burn combustion system. The reason is the higher amount of $\mathrm{O}_{2}$ and the reduced adiabatic combustion temperature with leaner mixtures that leads to enhanced $\mathrm{NO}$ oxidation into $\mathrm{NO}_{2}$. This high $\mathrm{NO}_{2}$ share in NOx is clearly an advantage for the application of deNOx systems such as NOx storage catalysts. Indeed, NOx molecules are only stored in the trap after oxidation of $\mathrm{NO}$ into $\mathrm{NO}_{2}$. Thus, NOx storage could be enhanced with this new ultra-lean combustion system.

Figure 19 (d) shows that optimal combustion timings can be reached with GDI whatever the $\lambda$ conditions are, thanks to the positive cooling effect related to fuel vaporization. It can also be observed that the optimal combustion timing is close to $5 \mathrm{CAD}$ aTDC which is slightly earlier than usual for stoichiometric engines. This optimal combustion timing has been identified based upon spark-timing variations performed for various engine configurations (not shown in this article). With PFI, combustion timing was delayed for $\lambda$ values up to around 1.7 because of the knock occurrence. Starting from $\lambda=1$, the positive effect of mixture dilution is progressively balancing the negative effect of increased intake pressure as the relative air/fuel dilution ratio $\lambda$ is increasing. Similar positive effects of mixture "en-leanment" on combustion phasing have been recently reported by Clasen et al. [18]. Consequently, at $\lambda>1.7$, the extreme dilution rate strongly supports the mitigation of knock and optimal combustion timings can also be reached with PFI. In parallel, similar combustion durations (MFB90-MFB10) are observed for GDI and PFI despite of the combustion delay up to $\lambda=1.6$ with PFI. Then, for extreme dilution rates, the combustion duration is higher for GDI than for PFI which can be related to the better air-fuel homogenization process with PFI. It can be assumed that the higher the $\lambda$ is, the more critical the impacts of mixture heterogeneities on flame propagation will be. This assumption is also supported by very early SOI timing for PFI (at 540 CAD bTDC) compared to the slightly more delayed one with GDI (at 300 CAD bTDC).

Finally, PFI main injection was identified as the optimal gasoline main injection configuration. Therefore, the remaining tests were conducted with this configuration.

\section{Comparison Between Gas and Gasoline Injection in the Pre-Chamber}

As PFI was identified as the optimal injection mode for the main chamber, the objective was then to compare the performance of the gas and gasoline fed pre-chambers. The optimal engine settings previously identified were applied for both pre-chambers (see Table $6)$. 
Table 6. Injection settings for gas and gasoline pre-chamber $\lambda$ variation (3000 rpm, 13 bar IMEP, $\lambda=1.67$ )

\begin{tabular}{|c|c|c|}
\hline Injection settings & Gas PC & Gasoline PC \\
\hline MFR PC $[\mathrm{kg} / \mathrm{h}]$ & 0.10 & 0.022 \\
\hline SOI PC [CAD bTDC] & 360 & 300 \\
\hline SOI PFI [CAD bTDC] & 540 & 140 \\
\hline
\end{tabular}

Figure 20 shows the comparison of both pre-chambers with PFI. The main result in chart (a) is that gasoline pre-chamber allowed to reach $\lambda=2$ operation and a higher maximum ITE of $46.9 \%$ whereas the gas pre-chamber was limited to $46 \%$. Ultra-lean mixtures with a dilution ratio up to $\lambda=2.1$ can be achieved with the gasoline pre-chamber, whereas the gas variant was limited to $\lambda=1.9$.

Here again, the smoke emissions measured with the gas pre-chamber are very high in ultra-lean conditions. Two main factors can explain this trend and have also been reported by Müller et al. [16]:

- CFD simulation results reported in Figure 12 showed that the critical area for the gas pre-chamber was located at the gas injector outlet. A very rich mixture can be expected in this area because of the specific design of this pre-chamber.

- The fuel mass flow rate in the pre-chamber is much higher for the gas variant than for the gasoline one $(0.1 \mathrm{~kg} / \mathrm{h}$ and $0.022 \mathrm{~kg} / \mathrm{h}$ respectively), even if both flow rates correspond to the minimal stable and repeatable amount that each fuel injector can deliver. This large difference certainly results in a richer average $\lambda$ in the case of gas pre-chamber.

These factors also affect the indicated thermal efficiency. In the case of the gasoline pre-chamber, less fuel in the pre-chamber also means directly more fuel in the main chamber to produce more piston work. Given the lower heating value of gas and the higher gas mass flow rate compared to gasoline, the gas pre-chamber is severely disadvantaged. Having more fuel and non-optimal $\lambda$ in the prechamber can also slow down the combustion process in the prechamber. The pressure increase in the pre-chamber might not be strong enough to enable the jets to efficiently ignite the mixture in the main chamber, especially in ultra-lean conditions. This could explain why the maximal dilution rate with the gas pre-chamber is lower than that with the gasoline pre-chamber (further analyses on this topic will be performed and detailed in another publication).

Figure 20 (b) shows that uHC emissions were equivalent for both pre-chambers. For very lean mixtures $(\lambda>1.6), \mathrm{CO}$ emissions are slightly lower for the gasoline pre-chamber, thus confirming that there could be either strong mixture heterogeneities or an overfueling in the gas fed pre-chamber when the combustion starts because of the injection settings.

Figure 20 (c) shows that $23 \mathrm{ppm}$ of NOx can be achieved at $\lambda=2.1$ with the gasoline fed pre-chamber. As shown before, the $\mathrm{NO}_{2} / \mathrm{NOx}$ ratio was here again close to $100 \%$ in these ultra-lean conditions.

Combustion timing was delayed for both pre-chambers at low $\lambda$ settings as shown in Figure 20 (d). This can be explained with the boundary condition that both pre-chambers were tested with PFI main injection which is prone to knock for the low $\lambda$-settings on this operating point (3000 rpm, 13 bar IMEP). For $\lambda>1.7$, combustion was optimally phased with MFB50 around 5 CAD aTDC, and combustion durations can be considered as equivalent for both prechambers.
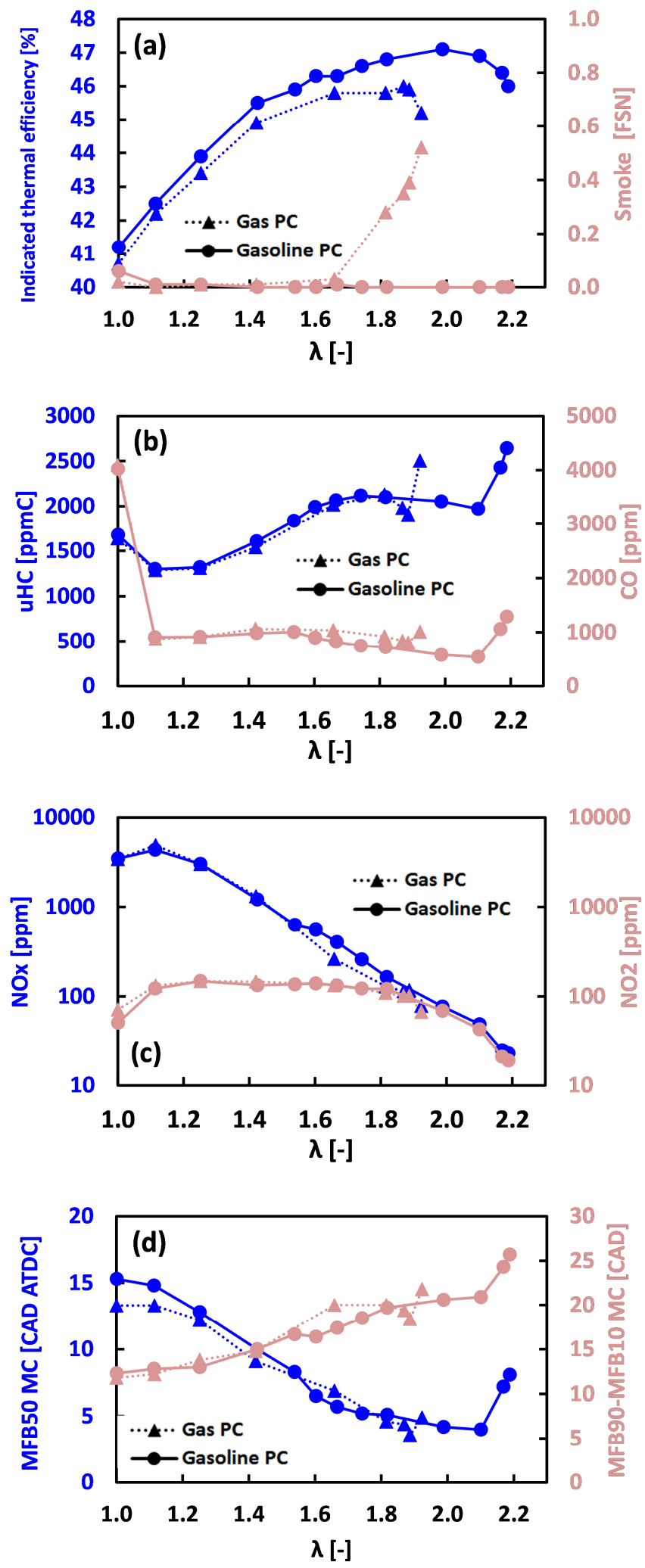

Page 12 of 15 
Under the given conditions, gasoline was identified as the optimal fuel for the pre-chamber which is also clearly an advantage in terms of infrastructure and engine complexity compared to a dual fuel engine.

\section{Effects of Differential Pressure Between Intake and Exhaust}

The differential pressure between intake and exhaust system was finally varied to evaluate the potential impacts of the turbocharging system on efficiency. The tests were done on the engine point $3000 \mathrm{rpm}$ engine speed 13 bar IMEP at $\lambda=2$. The engine configuration was PFI main gasoline injection with gasoline prechamber. Three levels of differential pressure settings were selected in order to be representative of different boosting systems:

- 0 mbar for a double-stage turbocharger optimized for this operating point.

- 500 mbar for a realistic electrified boosting system (including an e-turbo or an e-compressor).

- 900 mbar for an optimistic electrified boosting system.

The energy needed for powering electrified boosting devices is obviously not for free and should be taken into account in the global energy balance for the hybrid powertrain.

The intake and exhaust camshaft phasings were optimized for these tests in PFI mode switching from a reference positive overlap to a negative one with EVC/IVO = -4/-3 CAD aTDC (at $1 \mathrm{~mm}$ lift). The main reason for this change was to limit the fuel scavenging.
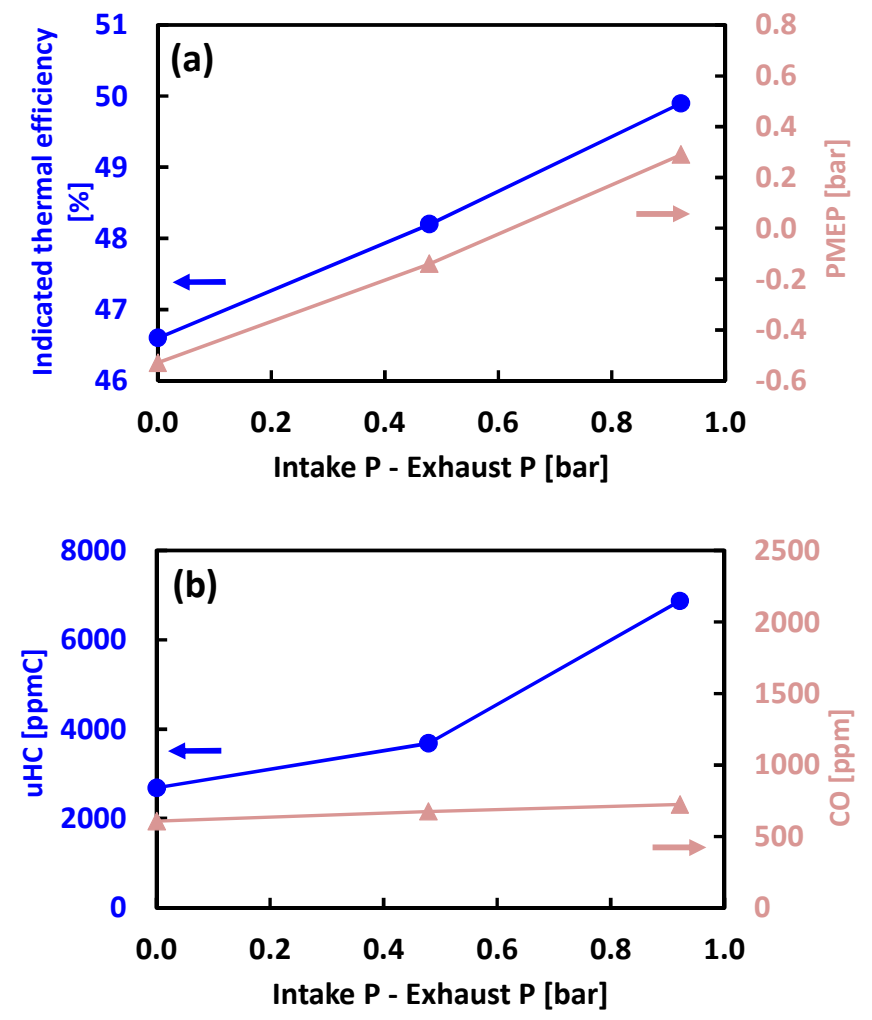

Figure 21. Differential pressure between intake and exhaust variation with PFI main injection and gasoline pre-chamber (3000 rpm, 13 bar IMEP, $\lambda=2$ ).

Figure 21 (a) shows that the indicated thermal efficiency can be linearly increased by around $1.8 \%$ absolute when increasing the differential pressure between intake and exhaust by 500 mbar. A maximal indicated efficiency of $50 \%$ was achieved for the most favorable considered conditions of 900 mbar thanks to a significant decrease in pumping losses (PMEP increases by +0.80 bar for 900 mbar differential pressure).

The main drawback of increasing the pressure difference between intake and exhaust is the high HC penalty shown in Figure 21 (b). These emissions, which are doubled between 0 mbar and 900 mbar, could be mostly explained by fuel scavenging which was possible because, even in these conditions, a small valve overlap is still remaining as shown in parallel by an increase in $\mathrm{O}_{2}$ concentrations at the exhaust when the differential pressure increases from 0 to 900 mbar (data not shown here). Consequently, this could be further optimized with reduced valve overlap.

\section{Perspectives}

Extremely high efficiencies have been obtained with the newly developed combustion system presented above. Nevertheless, some improvements are still possible to further increase the thermal efficiency.

The decrease in unburnt hydrocarbon emissions should be the main priority. Emissions in the order of a few grams per kilowatt hour are enough to significantly decrease the efficiency and not only the scavenging process should be controlled but also the combustion process by optimizing the pre-chamber ignition system. Starting from the current status, decreasing the uHC emissions by $30 \%$ would increase the efficiency by around $0.5 \%$ absolute.

Another option would be to further increase the compression ratio. As shown above, optimal knock-free combustion timings have been achieved in ultra-lean conditions. Higher compression ratios than 15:1 could thus be used with the same intake valve lift, or with even more extreme valve lift strategies to further increase the ratio between expansion and compression strokes.

Another critical challenge is the capability to inject small fuel quantities into the pre-chamber in a repeatable way. As shown above, the lower the gasoline mass flow rate injected in the pre-chamber is, the higher is the indicated thermal efficiency. The unusual prechamber operating conditions require to reduce the static mass flow rate and the shot-to-shot variations of these injectors in order to make the most of the pre-chamber capabilities in ultra-lean conditions and to improve the efficiency.

In a future step, the new combustion system will be validated on a multi-cylinder engine in order to demonstrate its potential in terms of peak efficiency and ultra-low tailpipe pollutant emissions. To this end, a complete exhaust after-treatment system including a three way catalyst, a gasoline particulate filter and a NOx storage catalyst will be tested. This multi-cylinder engine will also include an electrified turbocharging system to efficiently achieve $\lambda=2$ over the entire operating range.

Page 13 of 15 


\section{Conclusions}

A new combustion system has been designed and fully optimized for ultra-lean operation aiming at achieving very high efficiencies. 1D and 3D simulations were performed to support the engine definition, and a specific active pre-chamber ignition system was optimized to be operated with gas and gasoline. Then a single cylinder engine was tested with this new combustion system to validate the lean-burn capability regarding thermal efficiency and pollutant emissions. The main takeaways of this study are as follows:

- $\quad$ SOI timings in the main and pre-chambers had a smaller impact on efficiency than the fuel mass flow rate in the pre-chamber. In any case, these two parameters must be jointly tuned to optimize the mean $\lambda$ value at spark-timing in the pre-chamber.

- Under the given conditions, the optimal fuel mass flow rate in the pre-chamber was the minimal fuel quantity that the prechamber injector can deliver (both for gas and gasoline).

- Gasoline injection in the pre-chamber allowed to run the engine with relative air/fuel ratios exceeding $\lambda=2$. This was impossible with gas injection into the pre-chamber.

- In ultra-lean conditions, high smoke emissions were observed with gas fed pre-chamber because of its specific design and an excessive injected fuel mass flow rate (caused by the injector).

- The leaner the combustion is, the lower the NOx emissions are and the higher the $\mathrm{NO}_{2}$ to $\mathrm{NOx}$ ratio is. This could be a benefit for the application of a NOx storage catalyst.

- $47 \%$ peak thermal efficiency achieved at $\lambda=2.1$ with the gasoline fed pre-chamber and indicated thermal efficiencies above $48 \%$ can be expected with a realistic electrified turbocharging system.

\section{References}

1. $\mathrm{CO}_{2}$ emission standards for passenger cars and light-commercial vehicles in the European Union https://www.theicct.org/sites/default/files/publications/EU-LCVCO2-2030 ICCTupdate 201901.pdf, The International Council on Clean Transportation. Last access date: 1 April 2019.

2. Energy Technology Perspectives 2012: Pathways to a Clean Energy System, International Energy Agency, 2012, https://doi.org/10.1787/20792603.

3. Brossard, J-L., The Energy Mix and its Impact on Multiple Automotive Topics, SIA Powertrain conference, 2018.

4. Subramanian, V., Gillet, R., De Paola, G., Future Evolutions of Diesel Engine Technology and its Powertrain Trends Influencing $\mathrm{CO}_{2}$ Emissions in Europe, SIA Powertrain conference, 2018 .

5. Iida, N., Research and Development of Super-Lean Burn for High Efficiency SI Engine. Challenge for Innovative Combustion Technology to achieve 50\% Thermal Efficiency, 9th Conference on Modeling and Diagnostics for Advanced Engine Systems (COMODIA), 2017, https://doi.org/10.1299/jmsesdm.2017.9.PL-1.

6. Jung, D., Sasaki, K., Sugata, K., Matsuda, M. et al., "Combined Effects of Spark Discharge Pattern and Tumble Level on Cycleto-Cycle Variations of Combustion at Lean Limits of SI Engine Operation," SAE Technical Paper 2017-01-0677, 2017, https://doi.org/10.4271/2017-01-0677.

7. Moriyoshi, Y., Kuboyama, T., Kaneko, M., Yamada, T. et al., "Fuel Stratification Using Twin-Tumble Intake Flows to Extend Lean Limit in Super-Lean Gasoline Combustion," SAE
Technical Paper 2018-01-1664, https://doi.org/10.4271/2018-01-1664.

8. Mazda Next-generation Technology, Skyactiv-X nextgeneration gasoline engine (press information, October 2017, https://insidemazda.mazdausa.com/press-release/mazda-nextgeneration-technology-press-information/. Last access date: 1 April 2019.

9. Luszcz, P., Takeuchi, K., Pfeilmaier, P., Gerhardt, M., Adomeit, P., Brunn, A., Kupiek, C., Franzke, B., Homogeneous Lean Burn Engine Combustion System Development Concept Study, 18th Stuttgart International Symposium, 2018, https://doi.org/10.1007/978-3-658-21194-3 19.

10. Ratnak, S., Kusaka, J., Daisho, Y., Yoshimura, K. et al., "Experiments and Simulations of a Lean-Boost Spark Ignition Engine for Thermal Efficiency Improvement," SAE Int. J. Engines 9(1):379-396, 2016.

11. Nakata, K., Nogawa, S., Takahashi, D., Yoshihara, Y. et al., "Engine Technologies for Achieving 45\% Thermal Efficiency of S.I. Engine," SAE Int. J. Engines 9(1):2016, https://doi.org/10.4271/2015-01-1896.

12. Iafrate, N., Zaccardi, J-M., A Numerical Study on Charge Motion Effects in Ultra-Lean Conditions, Converge User Conference, 2018.

13. Trost, J., Laget, O., Cordier, M., Duffour, F., Gautrot, X., Increasing Modern Spark Ignition Engine Efficiency: Optimization of intake ports dedicated to Miller cycle, high dilution and increased compression ratio, SIA Powertrain Conference, 2017.

14. Bunce, M. and Blaxill, H., "Sub-200 g/kWh BSFC on a Light Duty Gasoline Engine," SAE Technical Paper 2016-01-0709, 2016, https://doi.org/10.4271/2016-01-0709.

15. Sens, M., Binder, E., Reinicke, P.-B., Rieß, M., Stappenbeck, T., Woebke, M., Pre-chamber Ignition and Promising Complementary Technologies, $27^{\text {th }}$ Aachen Colloquium Automobile and Engine Technology, 2018.

16. Müller, C., Habermann, K., Morcinkowski, B., Uhlmann, T., Schernus, C., Development of a Pre-chamber for Spark-Ignition Engines in Vehicle Applications, $4^{\text {th }}$ International Conference on Ignition Systems for Gasoline Engines, 2018, https://doi.org/10.5445/ir/1000088588.

17. Bozza, F., De Bellis, V., Tufano, D., Malfi, E. et al., "A QuasiDimensional Model of Pre-Chamber Spark-Ignition Engines," SAE Technical Paper 2019-01-0470, 2019, https://doi.org/10.4271/2019-01-0470.

18. Clasen, K., Koopmans, L., and Dahl, D., "Homogeneous Lean Combustion in a 21t Gasoline Direct Injected Engine with an Enhanced Turbo Charging System," SAE Technical Paper 201801-1670, 2018, https://doi.org/10.4271/2018-01-1670.

\section{Contact Information}

Jean-Marc Zaccardi

EAGLE Project Coordinator

Efficient Additivated Gasoline Lean Engine

https://www.h2020-eagle.eu/

j-marc.zaccardi@ifpen.fr

Phone: +33437 702063

\section{Acknowledgments}

This project has received funding from the European Union's Horizon 2020 research and innovation programme under grant agreement No 724084 .

Page 14 of 15 
The authors would like to acknowledge the contribution and support of many colleagues at IFPEN (Geoffrey Bourrachot, Nicolas Leblanc and Julien Trost), Renault S.A. (Maziar Dabiri), FEV Europe GmbH (Bastian Morcinkowski, Agnese Malpighi, Christopher Kupiek and Albert Jeckel), Danielson Engineering (Arnaud Delaitre) and CPT Group GmbH (Harry Schuele).

\section{Definitions/Abbreviations}

CAD

CoV

EGR

EIVC

EVC

FSN

GDI

HP/LP

IMEP

ISFC

ITE

IVO

MC

MFB
Crank Angle Degree

Coefficient of Variation

Exhaust Gas Recirculation

Early Intake Valve Closing

Exhaust Valve Closing

Filter Smoke Number

Gasoline Direct Injection

High/Low Pressure

Indicated Mean Effective Pressure

Indicated Specific Fuel

Consumption

Indicated Thermal Efficiency

Intake Valve Opening

Main Chamber

Mass Fuel Burnt
PC

PFI

PM

PMEP

PN

SI

SOI

$\mathbf{S} / \mathbf{V}$

TDC/aTDC/bTDC

TKE

uHC

WLTP

$\lambda$
Mass Flow Rate

Pre-Chamber

Port Fuel Injection

Particulate Mass

Pumping Mean Effective Pressure

Particle Number

Spark Ignition

Start of Injection

Surface-to-Volume ratio

Top Dead Center/after.../before...

Turbulent Kinetic Energy

unburnt Hydrocarbons

Worldwide harmonized Light vehicle Test Procedure

Relative air-fuel ratio 